\title{
DISTRIBUIÇÃO DA BIOMASSA E MINERAIS EM "FAMÍLIA" DE BANANEIRA 'PRATA-ANÃ'ADUBADA COM ZINCO VIA BROTO DESBASTADO ${ }^{1}$
}

\author{
MARIA GERALDA VILELA RODRIGUES², DILERMANDO DOURADO PACHECO ${ }^{3}$, \\ WILLIAM NATALE ${ }^{4}$, JOSÉ TADEU ALVES DA SILVA ${ }^{5}$, MÁRIO SÉRGIO CARVALHO DIAS ${ }^{6}$
}

RESUMO-O Norte de Minas Gerais cultiva basicamente bananeira 'Prata-Anã', cultivar especialmente exigente em zinco. A possibilidade de fornecimento de $\mathrm{Zn}$, sem que esse entre em contato com o solo, é importante para a região, uma vez que vários fatores levam à baixa disponibilidade do elemento fornecido via solo, como: elevado teor de matéria orgânica na camada superficial (resultante de resíduos culturais); manutenção de elevado $\mathrm{pH}$ do solo - acima de 6,00 - como estratégia contrária à proliferação do agente causal do mal-do-panamá; adubações frequentes com potássio e magnésio, que além de basificar o meio, diminuem a participação do Zn no equilíbrio cátion-ânion do solo, dificultando a absorção deste micronutriente pela planta. Para determinar a distribuição de biomassa e minerais na bananeira 'Prata-Anã', cultivada sob irrigação no norte de Minas Gerais, quando o zinco é fornecido via broto desbastado, foi conduzido um experimento no Perímetro Irrigado de Jaíba. As plantas foram adubadas com 0,00; 1,66 e 3,33 g.família-1 de $\mathrm{Zn}\left(0 ; 25\right.$ e 50 g.família ${ }^{-1}$.ano ${ }^{-1}$ de sulfato de $\left.\mathrm{Zn}\right)$, via muda desbastada. Um mês após as adubações de outubro de 2007 e junho de 2008, avaliaram-se a produção de massa fresca (MF) e massa seca (MS), os teores e conteúdos de minerais em todos os órgãos de uma "família" de bananeira composta por planta-mãe com cacho + planta-filha alta + planta-neta. As doses de Zn não influíram na produção de MF e MS das plantas na primeira avaliação, enquanto na segunda avaliação observou-se efeito positivo do tratamento apenas para MF acumulada nas folhas inferiores, nas porções do terço médio e inferior do pseudocaule, e no rizoma da planta-mãe. Tanto o teor quanto o acúmulo de nutrientes nas plantas-mãe apresentaram a seguinte ordem decrescente: $\mathrm{K}>\mathrm{N}>\mathrm{Ca}>\mathrm{Mg}>\mathrm{P}>\mathrm{S}>\mathrm{Fe}>\mathrm{Zn}>\mathrm{B}>\mathrm{Cu}$. Os teores de $\mathrm{Zn}$ foram afetados pela dose desse micronutriente na maioria das situações estudadas. O Zn fornecido via broto desbastado ascendeu na plantamãe, e daí se redistribuiu na "família" da bananeira.

Termos para indexação: adubação, nutrição de plantas, micronutriente, Musa sp.

\section{BIOMASS AND MINERALS DISTRIBUTION IN "FAMILY" OF BANANA 'PRATA-ANÃ' FERTILIZED WITH ZINC THROUGH THINNED SPROUT}

\begin{abstract}
In the North of Minas Gerais it is cultivated basically 'Prata-Anã' banana, a cultivar that requires mainly $\mathrm{Zn}$. The possibility of zinc supply, without this nutrient getting in contact with the soil, it is important for the region, since several factors take to the low availability of the element supplied by the soil, as: elevated organic matter content on the surface (from cultural residues); maintenance of high $\mathrm{pH}$ of the soil - above 6,00 - as strategy contrary to the proliferation of the causal agent of the Fusarium Wilt; frequent fertilizations with potassium and magnesium that, besides converting the medium into base, they reduce the participation of $\mathrm{Zn}$ in the balance cation/anion of the soil, hindering the absortion of this micronutrient by the plant. For determining the distribution of biomass and minerals in the 'Prata-Anã' banana, cultivated under irrigation in the North of Minas Gerais, when the zinc was supplied through thinned sprout, an experiment was carried out in the Irrigated Perimeter of Jaíba. The plants were fertilized with 0,$00 ; 1,66$ and 3,33 g.family ${ }^{-1}$ of $\mathrm{Zn}$, through thinned sprout. One month after the fertilizations from October 2007 and February 2008, the production of fresh mass (FM) and dry mass (DM) were evaluated, the contents and meanings of minerals in all the bananas "family" bodies composed by mother-plant with bunch + tall daughter-plant + granddaughter-plant. The doses of $\mathrm{Zn}$ did not influence on the production of FM and DM of the plants in the first evaluation, while in the second evaluation positive effect of the treatment was observed just for MF accumulated in the inferior leaves, in the portions of the medium third and inferior of the pseudostem, and in the mother-plant's rhizome. As much the content as the accumulation of nutrients in the mother-plants presented the following decreasing order: $\mathrm{K}>\mathrm{N}>\mathrm{Ca}>\mathrm{Mg}>\mathrm{P}>\mathrm{S}>\mathrm{Fe}>\mathrm{Zn}>\mathrm{B}>\mathrm{Cu}$. The $\mathrm{Zn}$ contents were affected by the dose of that micronutrient in the most of the studied situations. The zinc supplied through thinned sprout increased in the mother-plant, and then it was redistributed in the banana's "family". Index terms: fertilization, plants nutrition, micronutrient, Musa sp.
\end{abstract}

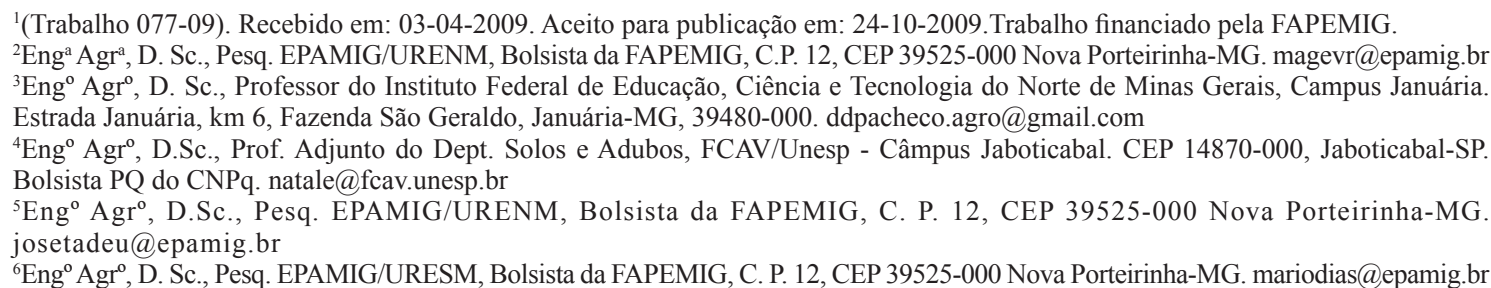

Rev. Bras. Frutic., Jaboticabal - SP, v. 32, n. 2, p. 599-611, Junho 2010 


\section{INTRODUÇÃO}

A bananeira absorve e exporta elevada quantidade de nutrientes, apresentando alta demanda para a obtenção de bom desenvolvimento e altos rendimentos (LÓPEZ ; ESPINOSA, 1995). A 'Prata-Anã' é especialmente exigente em zinco $(\mathrm{Zn})$, absorvendo quase duas vezes mais que a 'Grande Naine' (FARIA, 1997). No trabalho de Gomes et al. (1988), a sequência para o acúmulo decrescente de Zn na massa seca (MS) da bananeira 'Prata' foi: rizoma $>$ pseudocaule $>$ folha $>$ fruto $>$ engaço $>$ pecíolo $>$ botão floral; sendo que os dois primeiros órgãos absorveram $82 \%$ do $\mathrm{Zn}$, merecendo destaque a expressiva absorção pelo rizoma, que superou o pseudocaule, a folha e o fruto, mesmo tendo acumulado pouca matéria seca. Os autores concluíram que, provavelmente, nas células do rizoma, aconteçam atividades metabólicas importantes para a 'Prata', em maior escala do que nas demais. Esse resultado foi corroborado por Lahav (1995), que diz que o $\mathrm{Zn}$, assim como o sódio ( $\mathrm{Na}$ ), tendem a se acumular no rizoma.

Silva e Rodrigues (2001), avaliando o estado nutricional dos bananais do norte de Minas Gerais, verificaram que os micronutrientes foram deficientes em ordem decrescente: $\mathrm{Zn}>\mathrm{Cu}>\mathrm{Fe}>\mathrm{Mn}>\mathrm{B}$. O Zn apresentou-se deficiente em $72 \%$ das amostras foliares. Muitas destas áreas possuem elevadas concentrações de Zn no solo, resultantes de fertilização, o que sinaliza que o baixo teor foliar, incluindo a manifestação de sintomas visíveis de deficiência na planta possam ser decorrentes de inibições a processos como transporte no solo e absorção desse micronutriente pela planta.

Segundo Soto Ballestero (2000), a deficiência de $\mathrm{Zn}$ em bananeiras causa graves deformações no crescimento da planta e do cacho. O autor cita que, inicialmente, essa deficiência é semelhante à de nitrogênio $(\mathrm{N})$, porém diferenciando-se por apresentar, nos estágios posteriores, folhas estreitas com clorose e algumas necroses. Na carência aguda, observa-se clorose na totalidade do limbo das folhas novas, que são de tamanho menor, alongadas e com tendência a formar rosetas (LAHAV, 1995; SOTO BALLESTERO, 2000). Esses autores atribuem também à deficiência de $\mathrm{Zn}$ a ocorrência de frutos pequenos, malformados, com dedos curtos, retorcidos e cloróticos.

Vários são os fatores que, relacionados ao solo, à prática da adubação, às condições climáticas e intrínsecas à planta, podem causar deficiência de Zn. Entre estes, os solos arenosos, baixa CTC e sujeitos às chuvas pesadas; solos neutros e alcalinos; excesso de magnésio, potássio, ferro, manganês ou cobre ( $\mathrm{Mg}, \mathrm{K}, \mathrm{Fe}, \mathrm{Mn}$ ou $\mathrm{Cu}$ ); altas doses de $\mathrm{N}$ na adubação e restrições às raízes (MALAVOLTA, 1981). A deficiência de $\mathrm{Zn}$ está mais associada ao $\mathrm{pH}$ do que ao teor de $\mathrm{Zn}$ total no solo, uma vez que sua solubilidade é $\mathrm{pH}$ dependente. Segundo esse autor, é aceitável que a elevação do $\mathrm{pH}$ em uma unidade faz com que a concentração deste elemento na solução do solo diminua 100 vezes, provavelmente por insolubilização.

A possibilidade de fornecimento de $\mathrm{Zn}$, sem que esse entre em contato com o solo, é importante para os bananais do norte de Minas Gerais, uma vez que vários fatores levam à baixa disponibilidade do elemento fornecido via solo. Entre esses, está o elevado teor de matéria orgânica na camada superficial (resultante de resíduos culturais), o $\mathrm{pH}$ ser mantido elevado (acima de 6,0) em função da presença do agente causal do mal-do-panamá (Fusarium oxysporum f. sp. cubense), as frequentes adubações com $\mathrm{Mg}$, para equilibrá-lo com o $\mathrm{K}$ e o $\mathrm{Ca}$, uma vez que são feitas pesadas adubações com $\mathrm{K}$.

Saes e Quaggio (dados não publicados, citados por QUAGGIO;PIZZA JUNIOR, 2001) observaram resposta em teores foliares de $\mathrm{Zn}$ e B na planta adulta, 60 dias após aplicarem esses nutrientes na região meristemática do caule da bananeira, através do orifício deixado pelo desbastador "lurdinha". Essa forma de fornecimento de micronutrientes em bananeira é recomendada por Teixeira et al. (1997) e Moreira (1999 e 2001). Entretanto, em trabalho realizado por Rodrigues et al. (2007), com fornecimento de $\mathrm{Zn}$ e B diretamente no rizoma da bananeira 'Prata-Anã', não foi observado efeito na produção e nos teores foliares de nutrientes.

O presente trabalho objetivou determinar a distribuição do Zn na bananeira Prata-Anã, cultivada sob irrigação no norte de Minas Gerais, quando fornecido via broto desbastado, através da determinação dos pontos de acúmulo do nutriente.

\section{MATERIAL E MÉTODOS}

O experimento foi realizado na Fazenda Experimental de Mocambinho (FEMO), pertencente à Empresa de Pesquisa Agropecuária de Minas Gerais (EPAMIG). A FEMO localiza-se no Perímetro Irrigado de Jaíba, norte do Estado. A área experimental encontra-se nas coordenadas $48^{\circ} 05^{\prime} 29^{\prime \prime} \mathrm{O}$ e $15^{\circ} 06^{\prime} 48^{\prime \prime}$ $\mathrm{S}, 452 \mathrm{~m}$ de altitude, e o solo foi classificado como Latossololo Vermelho-Amarelo distrófico, com $220 \mathrm{~g}$ $\mathrm{kg}^{-1}$ de argila, $680 \mathrm{~g} \mathrm{~kg}^{-1}$ de areia e $100 \mathrm{~g} \mathrm{~kg}^{-1}$ de silte. O clima é Aw, segundo a classificação de Köeppen (JACOMINE et al., 1979). 
O bananal foi implantado com mudas de 'Prata-Anã' micropropagadas, no espaçamento de $3,0 \times 2,7 \mathrm{~m}$, irrigado por microaspersão. Optou-se por essa área por se tratar de um bananal estabilizado ( 9 anos), vigoroso e em franca produção, com histórico de alta concentração de $\mathrm{Zn}$ no solo, apesar de baixos teores foliares do elemento. Desde o plantio, a área foi conduzida conforme recomendações da EPAMIG para bananeira 'Prata-Anã' cultivada na região, posteriormente reunidas no Informe Agropecuário n. 245 (RODRIGUES et al., 2008). A irrigação foi manejada conforme evapotranspiração medida por Tanque Classe A. Foi feita manutenção com adubações mensais baseadas em resultados analíticos de amostras de solo e folhas coletadas a cada quatro meses.

Os tratamentos foram estabelecidos por percentuais das doses de $\mathrm{Zn}$ recomendadas para aplicação via solo: testemunha (dose zero), 50 e $100 \%$ dos $10 \mathrm{~g}$ de $\mathrm{Zn}$ recomendados por família (BORGES et al., 1987; SILVA et al., 1999), que resultaram nas doses de $0 ; 5$ e 10 g.família ${ }^{-1}$.ano ${ }^{-1}$ de $\mathrm{Zn}$, ou seja, 0; 25 e 50 g.família ${ }^{-1}$.ano ${ }^{-1}$ de sulfato de $\mathrm{Zn}(20 \%$ de $\mathrm{Zn}$ ). Cada uma dessas doses anuais foi dividida em três aplicações de 0,0; 8,3 e 16,6 g de sulfato de $\mathrm{Zn}$ família $^{-1}$, respectivamente. O fertilizante sulfato de zinco foi fornecido diretamente na planta, através de perfuração feita com o desbastador "lurdinha", conforme metodologia recomendada por Teixeira et al. (1997) e Moreira (1999 e 2001). O desbastador "lurdinha" foi empregado para extrair a gema apical de um broto cortado rente ao solo, de forma que, no local, ficasse um orifício onde o fertilizante foi aplicado.

Cada tratamento foi aplicado em 20 "famílias" distribuídas aleatoriamente no bananal e mantido por cinco anos consecutivos (2003 a 2008). Um mês após as adubações de outubro de 2007 e de junho de 2008, foram coletadas plantas para avaliação. De cada um dos três tratamentos (doses de $\mathrm{Zn}$ ), foram avaliadas duas "famílias" de bananeira, por época (novembro de 2007 e julho de 2008), totalizando 12 "famílias" amostradas. As "famílias" amostradas foram selecionadas por representarem o estádio de desenvolvimento em que se encontrava a maioria das 60 "famílias" que receberam tratamento.

$\mathrm{Na}$ primeira avaliação, foram selecionadas famílias que apresentavam planta-mãe com cacho + planta-filha alta + planta-neta. Na segunda avaliação, feita no inverno, quando o desenvolvimento das plantas é menor, foram selecionadas famílias compostas por planta-mãe próxima à floração + planta-filha de porte médio + planta-neta ainda não definida ou pequena.

De cada planta da família, foram avaliados: o receptáculo (porção residual da muda que foi cortada e que recebeu o adubo), rizoma (na planta-mãe foi amostrado o lado adjacente e o lado oposto ao ponto onde se encontrava o receptáculo, denominados de rizoma adubado e rizoma não adubado, respectivamente), pseudocaule (terço superior, médio e inferior), folhas (porção superior, média e inferior, compostas pela folha-bandeira ou a folha-vela + as três folhas seguintes; pelas folhas intermediárias e pelas folhas restantes, respectivamente), cacho, quando presente (eixo floral separado em engaço e ráquis, segunda e penúltima penca, coração).

Cada uma das partes da "família" foi pesada na sua totalidade e na forma de uma de suas porções: MFT (matéria fresca total) e MFA (matéria fresca da amostra), respectivamente. As partes em que se determinou a MFA foram secadas em estufa com circulação forçada de ar a $65^{\circ} \mathrm{C}$ até se obter uma massa constante (MS amostra). Fez-se, então, o cálculo da MS total de cada parte das plantas. Como amostra dos frutos, foram utilizados os seis frutos centrais da segunda e da penúltima pencas.

As amostras secas foram moídas e nestas determinados os teores de $\mathrm{N}$-total pelo método Kjeldahl (digestão sulfúrica) (TEDESCO et al., 1985); de P, pelo método da vitamina C (BRAGA;DEFELIPO, 1974); de K, por fotometria de chama (DEFELIPO; RIBEIRO, 1997); de S, por turbidimetria de sulfato (BLANCHAR et al., 1965); de Ca, Mg, Cu, Fe, Mn e Zn, por espectrofotometria de absorção atômica; e de B, por digestão via seca, seguida de dosagem com azometina-H (MALAVOLTA et al., 1997). Os dados de matéria fresca (MF) e matéria seca (MS) totais associados aos teores de minerais permitiram calcular os conteúdos nutricionais em cada órgão nas "famílias" de bananeira.

Pelo reduzido número de plantas amostradas, não foi utilizada análise estatística dos resultados. Todos os dados observados integraram as tabelas, exceto os dados de composição mineral, que são a média de dois valores.

\section{RESULTADOS E DISCUSSÃO}

As plantas-mãe da primeira avaliação (novembro) eram mais altas e apresentavam maior perímetro de pseudocaule que as plantas-mãe da segunda avaliação (julho), além de possuírem plantas-filhas altas, provavelmente com floração já diferenciada (Tabelas 1 e 2). As plantas de cada avaliaçãpo apresentavam-se bastante homogêneas. O cacho, quando presente, era pequeno, uma vez que ainda se encontrava em fase de crescimento. As plantas-filha também eram semelhantes entre si, porém não tanto 
quanto as plantas-mãe. Essa diferença provavelmente se deveu à época de coleta das amostras, já que os bananais se desenvolvem mais no verão.

A produção de MF e MS das plantas-mãe não foi afetada pelas doses de $\mathrm{Zn}$ (Tabelas 1 e 2). As plantas-mãe apresentaram médias de 9,3 e 7,0 $\%$ de MS, respectivamente, na primeira e segunda avaliação (Tabela 3), devendo-se isto à maior juvenilidade das plantas na segunda amostragem. A MS foi distribuída na planta, nas duas avaliações, de forma desuniforme: o órgão que mais acumulou MS foi o pseudocaule, seguido do rizoma e das folhas. Entretanto, proporcionalmente, as folhas foram mais ricas em MS, seguidas pelo rizoma e pseudocaule (Tabela 3).

Os teores de nutrientes foram muito altos no receptáculo, o que pode ser explicado pelo resíduo da adubação, no caso do Zn aplicado via muda desbastada e à contaminação pelos nutrientes presentes no solo. Assim, os conteúdos minerais vinculados a tal órgão foram desconsiderados nos cálculos para conteúdo total de nutriente na família. A contaminação deveu-se ao contato direto com o solo e à podridão já iniciada ter dificultado sua limpeza.

Os teores, conteúdos e distribuição dos nutrientes (percentagem do nutriente contido na MS da parte avaliada, em relação à MS total da família) nos diversos órgãos ao longo da primeira e segunda avaliações encontram-se nas Tabelas 4 a 11. A variação entre os teores e conteúdos nas diferentes partes da planta foi bastante acentuada para alguns nutrientes, porém ocorreu pouca variação em função das doses de $\mathrm{Zn}$.

As alterações nos teores de macro e micronutrientes não seguiram um padrão, invertendo o resultado conforme a amostra. Os teores de $\mathrm{Zn}$, entretanto, foram claramente afetados pela dose do elemento fornecida, apesar de não o serem em todas as partes da planta. Nas plantas-filha, esse efeito foi menos claro.

$\mathrm{O}$ receptáculo das famílias submetidas às doses de 5 e 10 g.família- .ano $^{-1}$ de Zn apresentou altíssimo teor de $\mathrm{Zn}$, nas duas avaliações, provavelmente por apresentar resíduos do adubo. A parte do rizoma adjacente ao receptáculo (rizoma adubado) apresentou teores e conteúdo de $\mathrm{Zn}$ superiores à parte contrária ao receptáculo (rizoma não adubado), indicando a entrada do elemento na planta.

A distribuição de Zn na planta foi evidenciada pelo gradiente entre receptáculo, rizoma adubado, rizoma não adubado, terços inferior, médio e superior do pseudocaule, nas doses de 5 e 10 g.família ${ }^{-1}$.ano ${ }^{-1}$ de $\mathrm{Zn}$, com significativas diferenças entre si. Em todas as situações, verificou-se diferença entre tratamentos, excetuando-se a avaliação do terço superior do pseudocaule da planta-mãe na primeira avaliação, nas primeiras folhas e nas folhas centrais, na segunda avaliação. Nas plantas-filha não se observou efeito dos tratamentos no teor de $\mathrm{Zn}$ nos tecidos, nas duas avaliações.

Mesmo sendo desejada uniformidade quanto ao estádio de desenvolvimento das “famílias", poucas eram as famílias que apresentavam plantas no ponto de coleta de amostra foliar. Porém, as que mais se aproximavam dessa fase eram as plantas-filha da primeira avaliação e as plantas-mãe na segunda avaliação, que estavam próximas ao ponto de floração. Nessas plantas, não ocorreu efeito da dose de Zn nos teores foliares de $\mathrm{Zn}$ no grupo foliar de onde se retira a amostra diagnose. Esse resultado está de acordo com o trabalho de Rodrigues et al. (2008), que também não observou efeito da adubação com $\mathrm{Zn}$.

Tanto o teor quanto o acúmulo de nutrientes nas plantas-mãe apresentaram a seguinte ordem decrescente: $\mathrm{K}>\mathrm{N}>\mathrm{Ca}>\mathrm{Mg}>\mathrm{P}>\mathrm{S}>\mathrm{Fe}>\mathrm{Zn}>\mathrm{B}>$ $\mathrm{Cu}$. $\mathrm{O}$ acúmulo médio de nutrientes nas plantas-mãe foi de: $60 \mathrm{~g}$ de $\mathrm{K} ; 7,6 \mathrm{~g}$ de $\mathrm{N} ; 6,4 \mathrm{~g}$ de $\mathrm{Ca} ; 3,4 \mathrm{~g}$ de $\mathrm{Mg} ; 1,7 \mathrm{~g}$ de $\mathrm{P} ; 1,3 \mathrm{~g}$ de $\mathrm{S} ; 762 \mathrm{mg}$ de $\mathrm{Zn} ; 124 \mathrm{mg}$ de $\mathrm{B}$ e $80 \mathrm{mg}$ de $\mathrm{Cu}$. 
TABELA 1 -Caracterização das plantas avaliadas em novembro de 2007 (verão), por: altura da planta (AP), perímetro do pseudocaule a $30 \mathrm{~cm}$ do solo (PP), comprimento da terceira folha (CTF), largura da terceira folha (LTF), número de folhas (NF), número de pencas do cacho (NPC), massa do cacho (MC), matéria fresca (MF) e matéria seca (MS).

\begin{tabular}{cccccccccccccc}
\hline \multirow{2}{*}{$\begin{array}{c}\text { Zn } \\
\left(\text { g.família-1 } \text { ano }^{-1}\right)\end{array}$} & Repetição & \multicolumn{4}{c}{ Planta-mãe } & \multicolumn{4}{c}{ Planta-filha } \\
\cline { 3 - 12 } & & $\begin{array}{c}\text { AP } \\
(\mathrm{m})\end{array}$ & $\begin{array}{c}\text { PP } \\
(\mathrm{m})\end{array}$ & $\begin{array}{c}\text { CTF } \\
(\mathrm{m})\end{array}$ & $\begin{array}{c}\text { LTF } \\
(\mathrm{m})\end{array}$ & NF & NPC & $\begin{array}{c}\text { MC } \\
(\mathrm{kg})\end{array}$ & $\begin{array}{c}\text { MF* } \\
(\mathrm{kg})\end{array}$ & $\begin{array}{c}\text { MS* } \\
(\mathrm{kg})\end{array}$ & $\begin{array}{c}\text { AP } \\
(\mathrm{m})\end{array}$ & $\begin{array}{c}\text { PP } \\
(\mathrm{m})\end{array}$ \\
\hline 0 & 1 & 4,40 & 1,42 & 2,50 & 0,96 & 17 & 13 & 7,750 & 258,36 & 23,27 & 2,72 & 0,82 \\
0 & 2 & 4,47 & 1,39 & 2,40 & 0,93 & 17 & 14 & 5,180 & 221,15 & 18,11 & 2,27 & 0,64 \\
5 & 1 & 4,00 & 1,28 & 2,18 & 0,90 & 17 & 13 & 6,205 & 211,66 & 20,02 & 2,13 & 0,68 \\
5 & 2 & 4,32 & 1,38 & 1,90 & 0,98 & 19 & 12 & 8,435 & 257,02 & 27,72 & 2,00 & 0,66 \\
10 & 1 & 4,49 & 1,46 & 2,28 & 0,93 & 15 & 14 & 15,755 & 268,00 & 25,65 & 3,25 & 1,05 \\
10 & 2 & 4,10 & 1,32 & 2,40 & 0,88 & 15 & 12 & 6,275 & 236,94 & 20,91 & 2,74 & 0,83 \\
\hline
\end{tabular}

* MF e MS das plantas, desconsiderando o cacho e raízes.

TABELA 2 - Caracterização da planta-mãe, das famílias avaliadas em julho de 2008 (inverno).

\begin{tabular}{ccccccc}
\hline $\begin{array}{c}\text { Zn } \\
\left(\text { g.família }{ }^{-1} \text { ano }^{-1} \text { ) }\right.\end{array}$ & Repetição & $\begin{array}{c}\text { Altura da } \\
\text { planta }(\mathrm{m})\end{array}$ & $\begin{array}{c}\text { Perímetro do } \\
\text { pseudocaule a 30 } \\
\text { cm do solo }(\mathrm{m})\end{array}$ & $\begin{array}{c}\text { Comprimento da } \\
\text { terceira folha (m) }\end{array}$ & $\begin{array}{c}\text { Matéria } \\
\text { Fresca* } \\
(\mathrm{kg})\end{array}$ & $\begin{array}{c}\text { Matéria } \\
\text { Seca* } \\
(\mathrm{kg})\end{array}$ \\
\hline 0 & 1 & 3,64 & 1,21 & 1,4 & 145,64 & 8,59 \\
0 & 2 & 4,07 & 1,33 & 1,5 & 188,59 & 11,51 \\
5 & 1 & 3,42 & 1,02 & 1,4 & 104,21 & 6,53 \\
5 & 2 & 4,20 & 1,42 & 1,7 & 206,94 & 13,16 \\
10 & 1 & 4,02 & 1,37 & 1,5 & 232,19 & 16,81 \\
10 & 2 & 3,68 & 1,28 & 1,8 & 202,48 & 13,95 \\
\hline
\end{tabular}

* MF e MS das plantas, desconsiderando o cacho e raízes.

TABELA 3 -Produção de matéria fresca (MF) e matéria seca (MS) pela planta-mãe.

\begin{tabular}{lcccc}
\hline & Folhas & Pseudocaule & Rizoma & Total \\
\hline \multicolumn{5}{c}{ Primeira avaliação (novembro) } \\
MF (kg) & 26,7 & 159,2 & 55,9 & 241,8 \\
MS (kg) & 5,0 & 10,1 & 7,5 & 22,6 \\
\% de MS & 18,7 & 6,3 & 13,4 & 9,3 \\
\hline \multicolumn{5}{c}{ Segunda avaliação (julho) } \\
MF (kg) & 18,7 & 125,0 & 46,0 & 189,8 \\
MS (kg) & 3,0 & 5,7 & 4,7 & 13,3 \\
$\%$ de MS & 16,2 & 4,5 & 10,1 & 7,0 \\
\hline
\end{tabular}


.

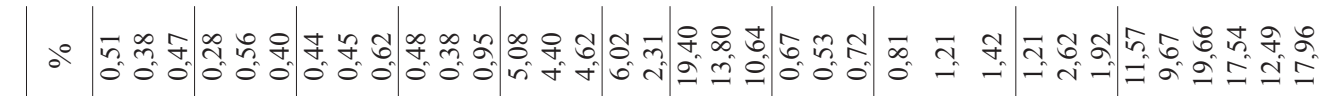

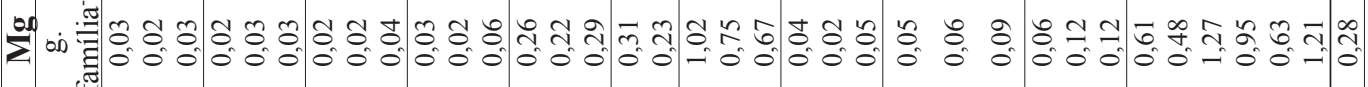
top 어

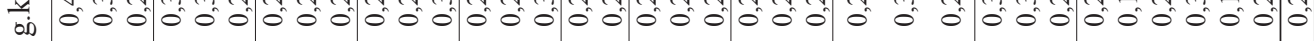

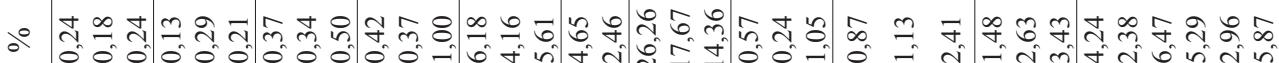

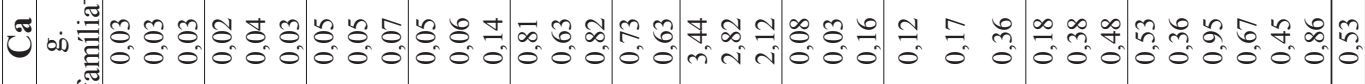

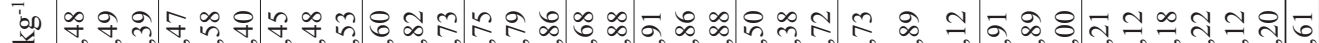

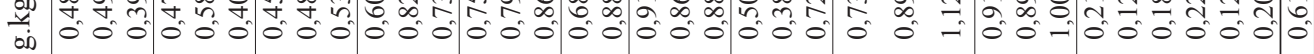

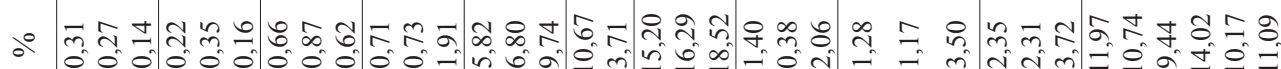

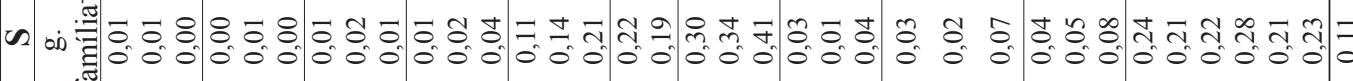
ช

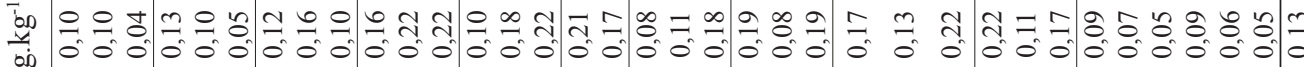

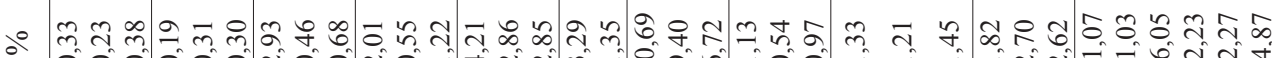
t) \%

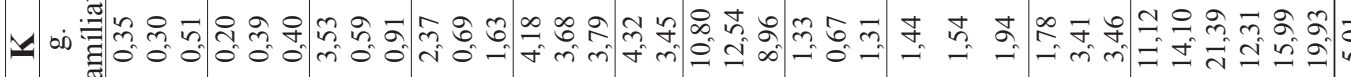

。ㄹ

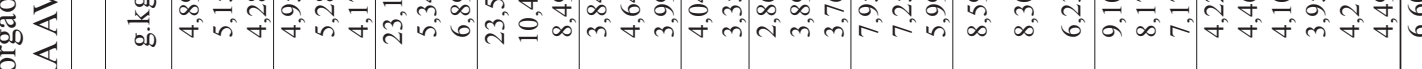

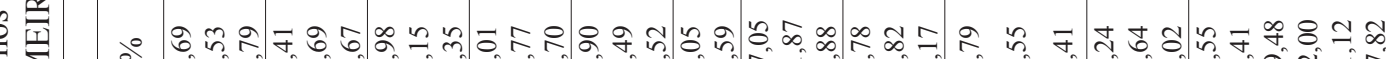

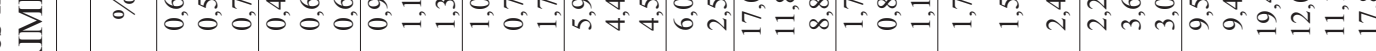

-

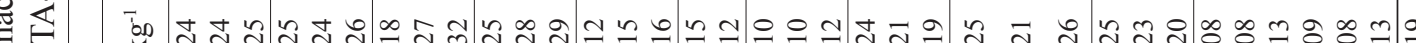

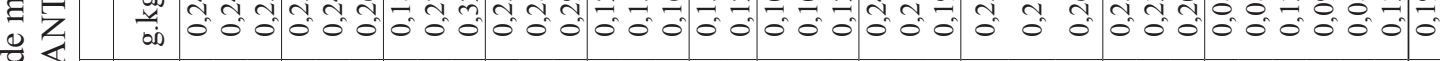

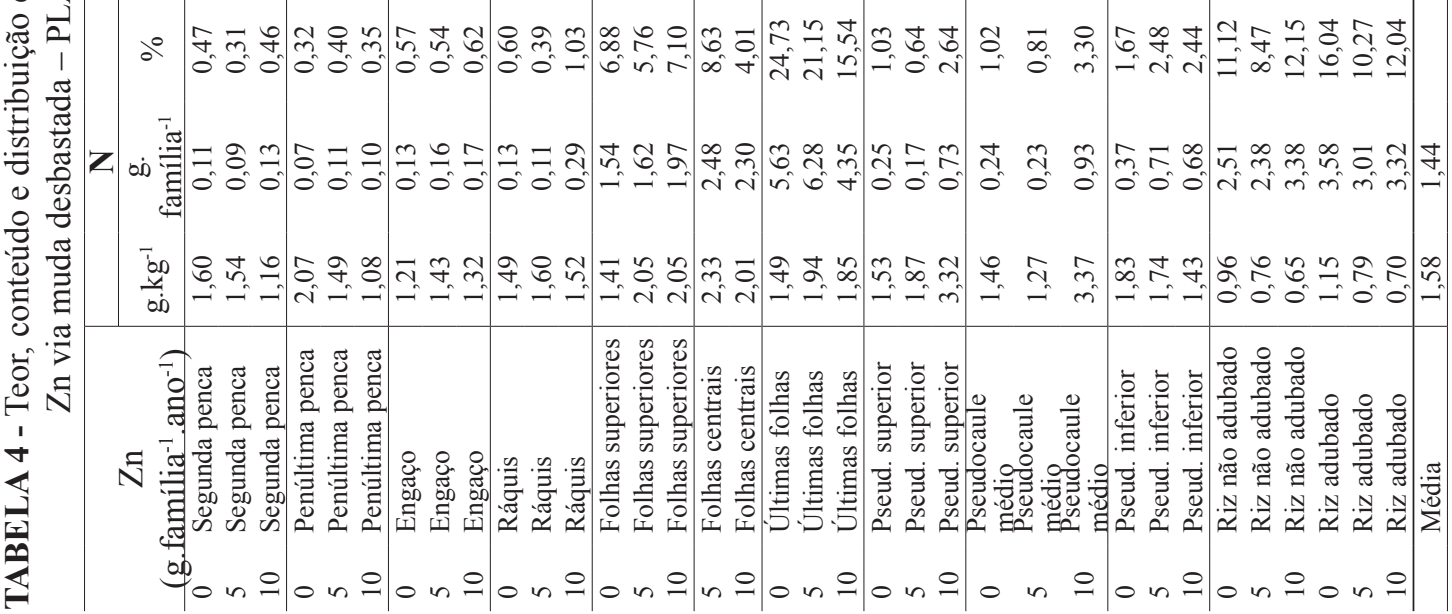


๑

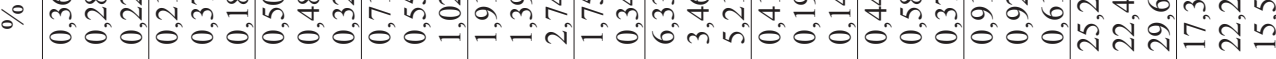

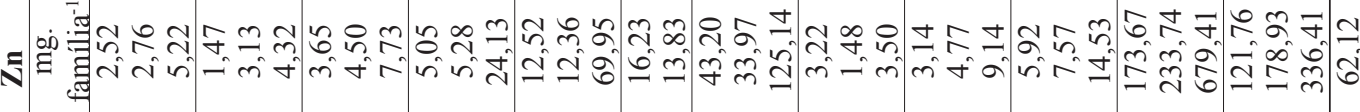

“

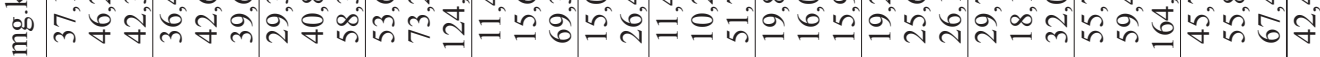

ㅇ సิ

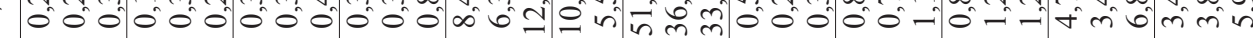

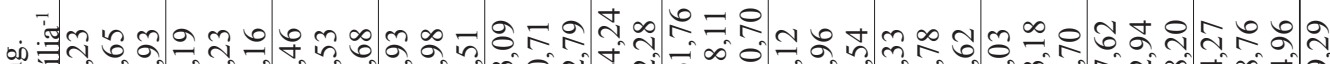

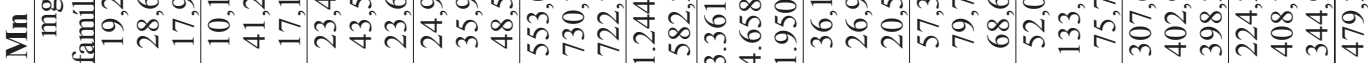

ธด

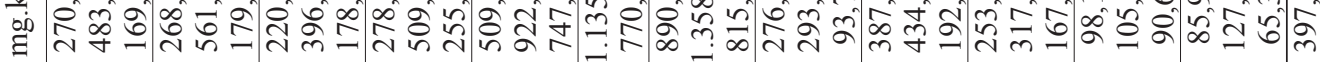

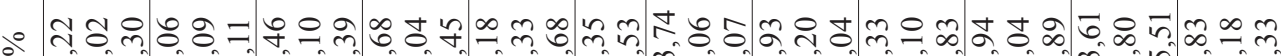

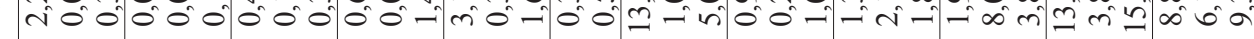

由 ज्ञ

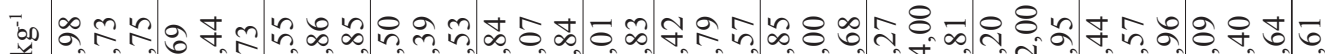

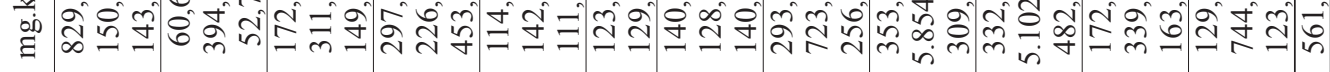

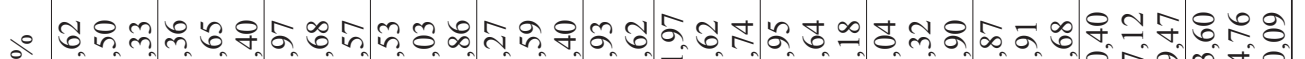

峁

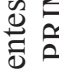

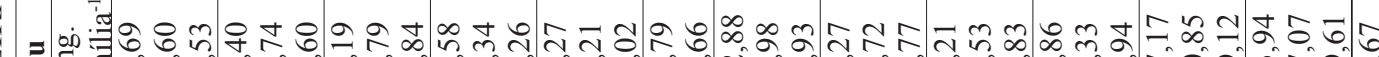

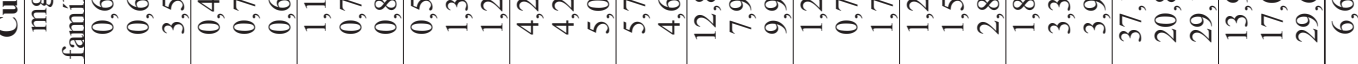

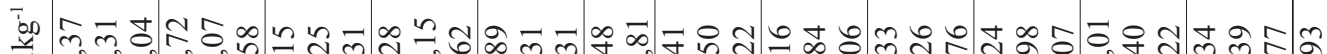

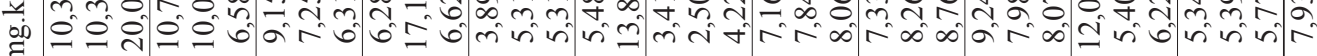

읏

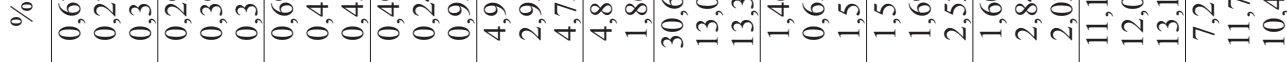

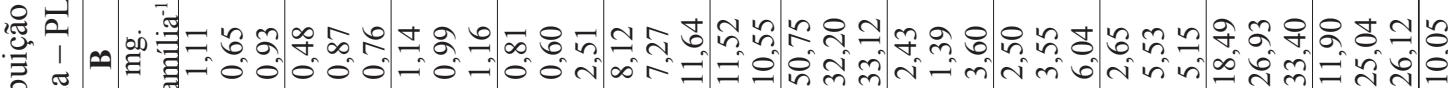
泀

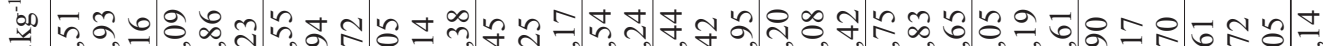
घं

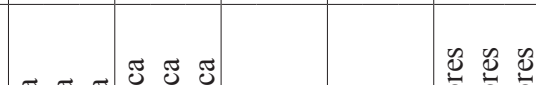

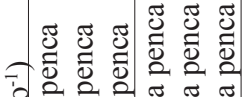

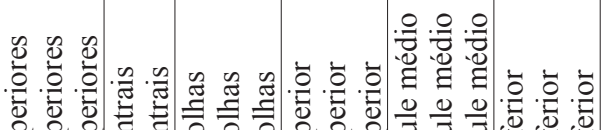

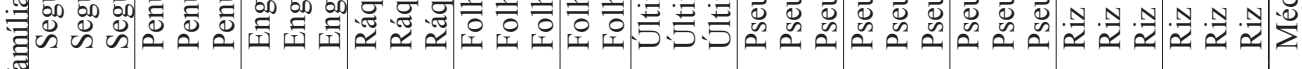

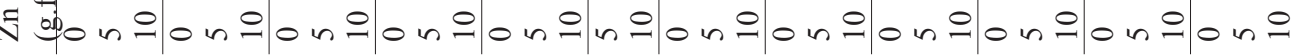


वृ.

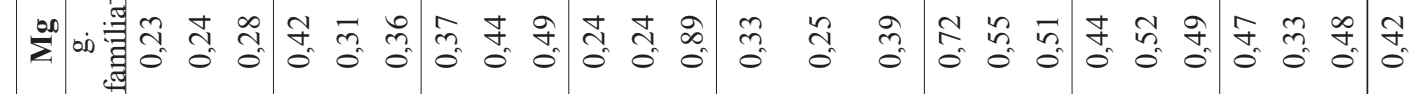

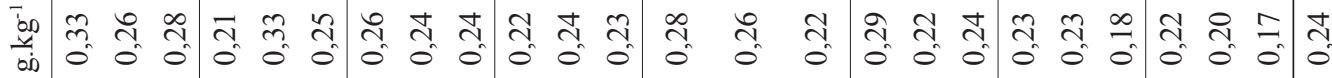

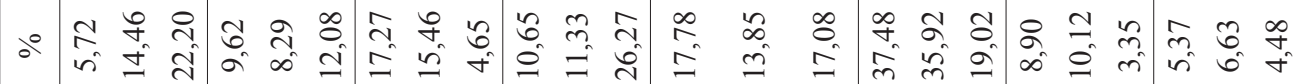

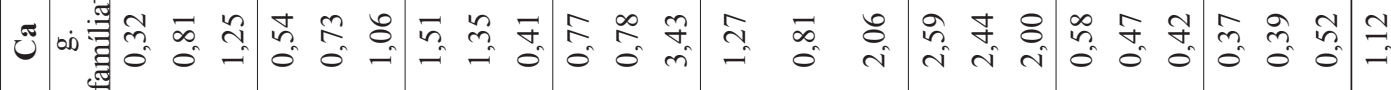

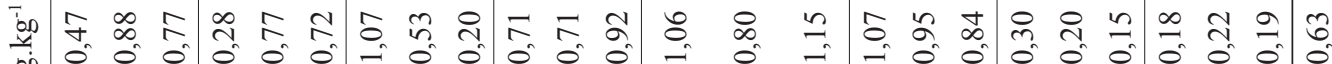

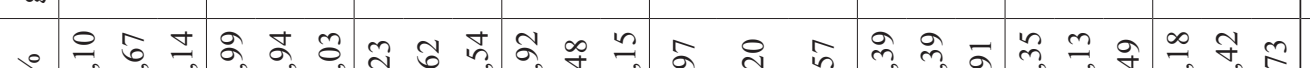

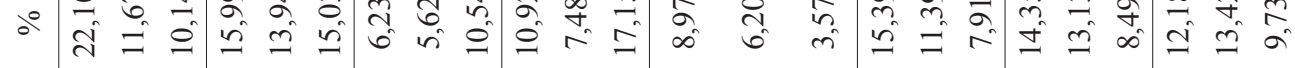

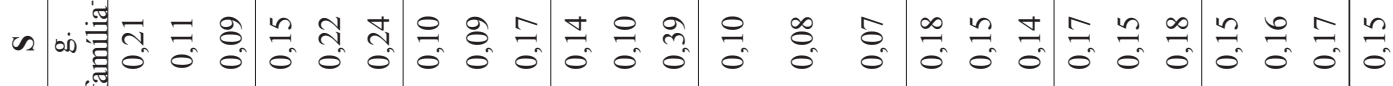

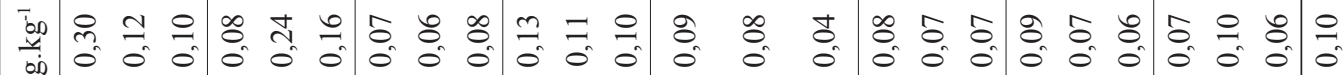
总 .0 ष 空

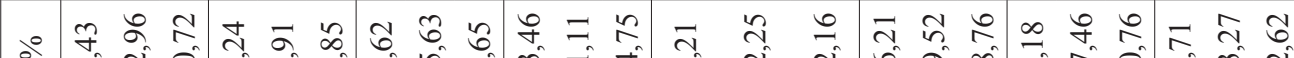

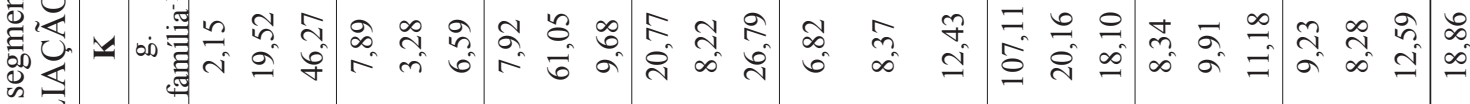

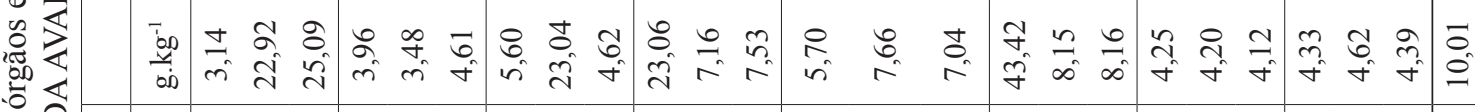

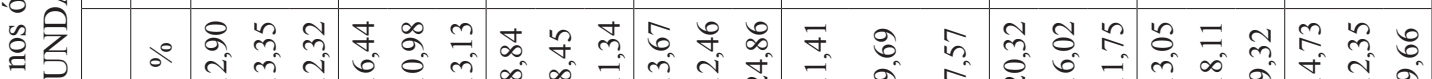

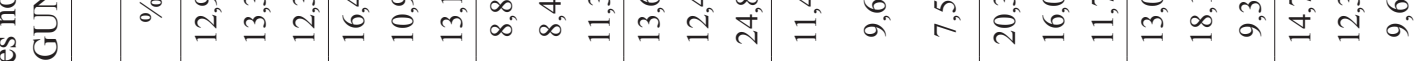
焉望

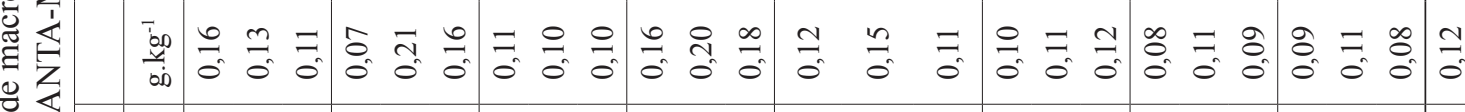

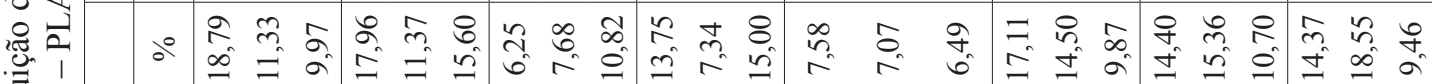

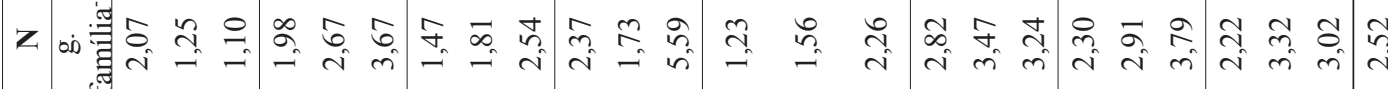

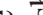

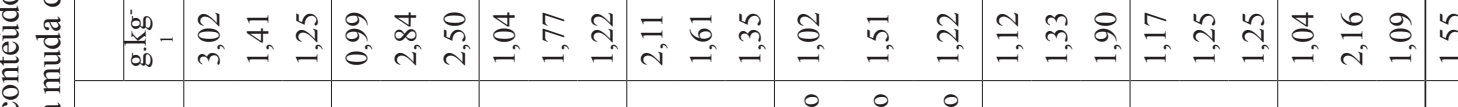

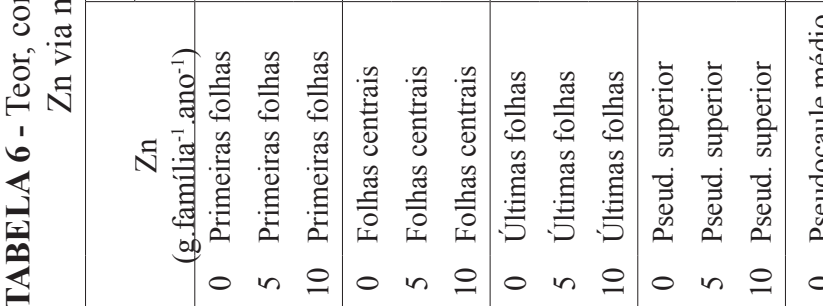




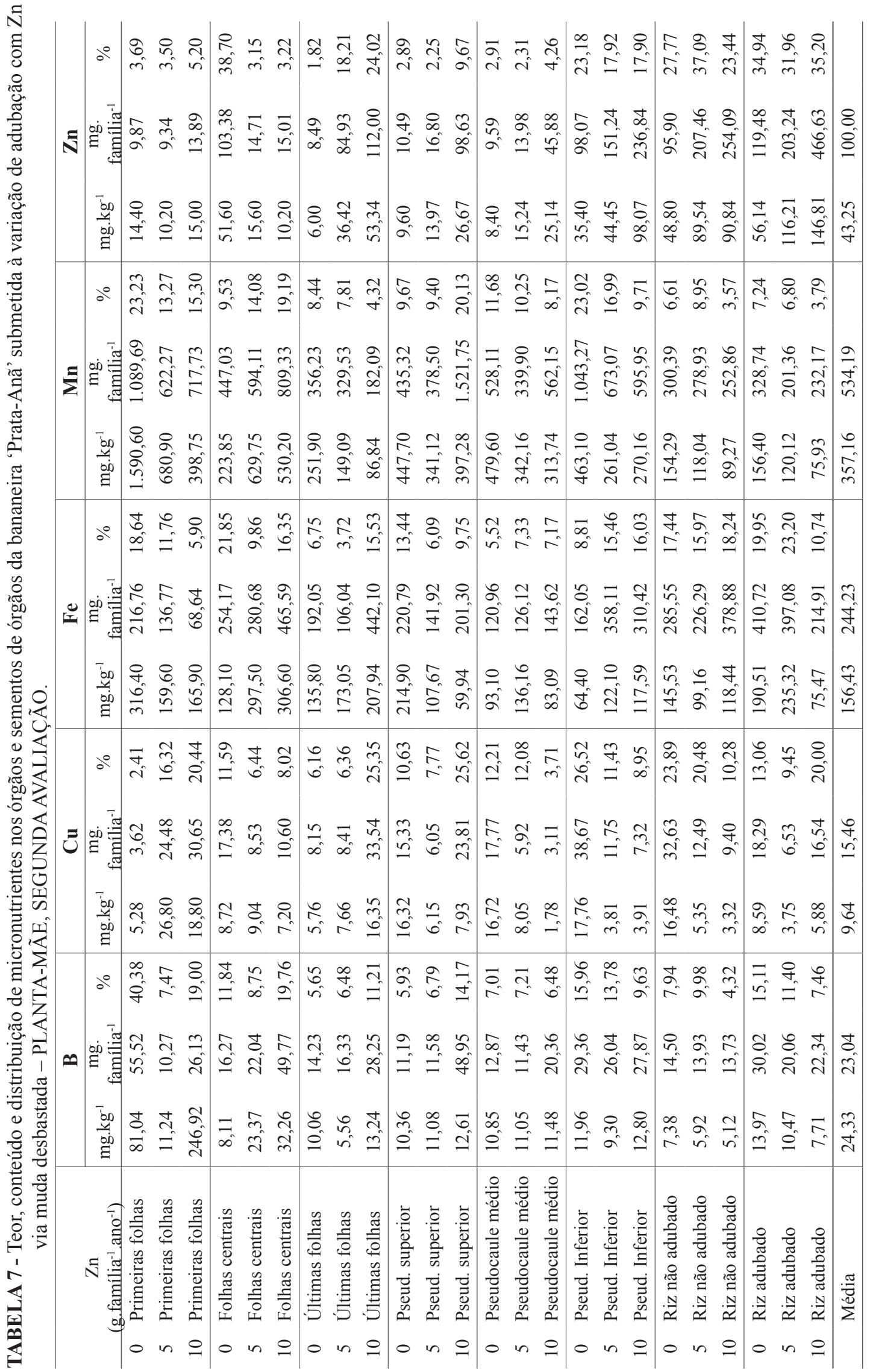




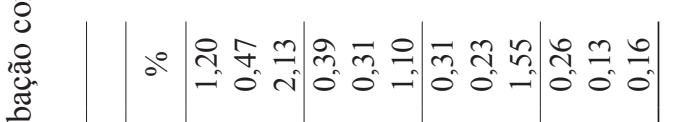

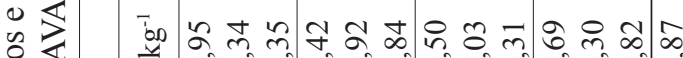

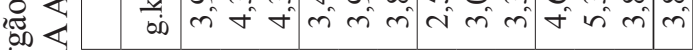

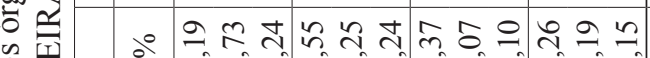

告

兽

쿠

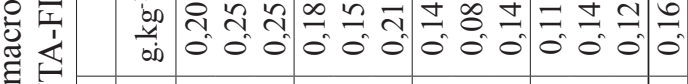

ข

म ती

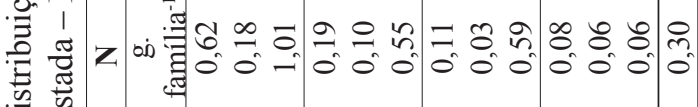

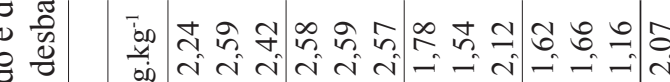
D. $\simeq \simeq$

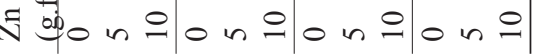

ఫ్ర

吾

to

เู่

敢

id

$\frac{\pi}{7}$

क

if

की

कृ.

$\stackrel{2}{0}$

क्ष

क्ष

$0 \ll$

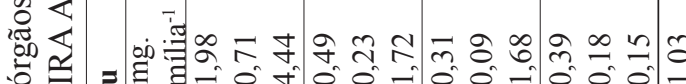
约

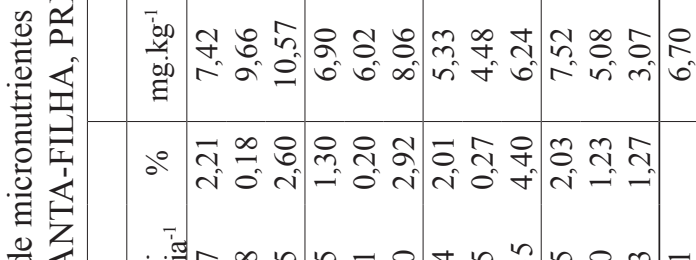

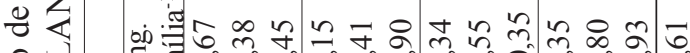

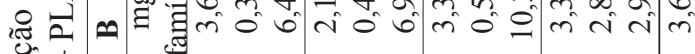

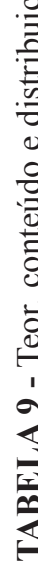

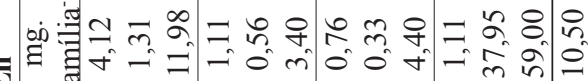
ฟิ

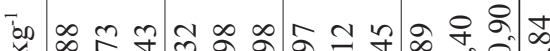
ఏ

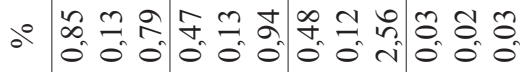

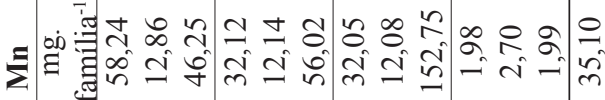

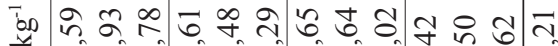

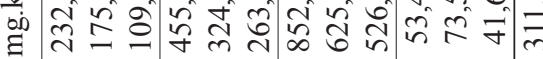

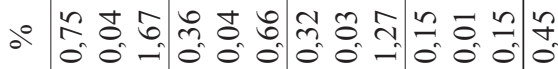
ம்

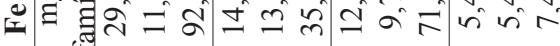
๒ิ ఏo

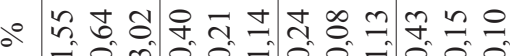

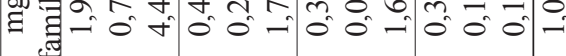
$\frac{\pi}{\pi}$ כூ

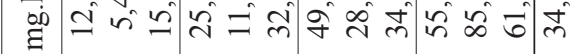

0

음

曾

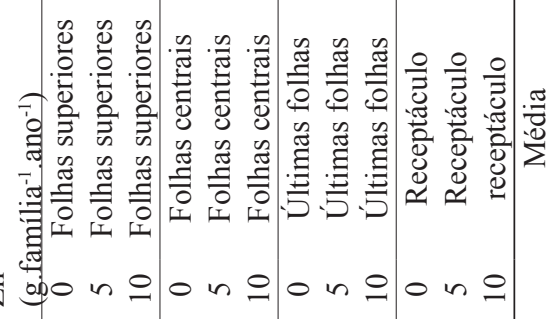



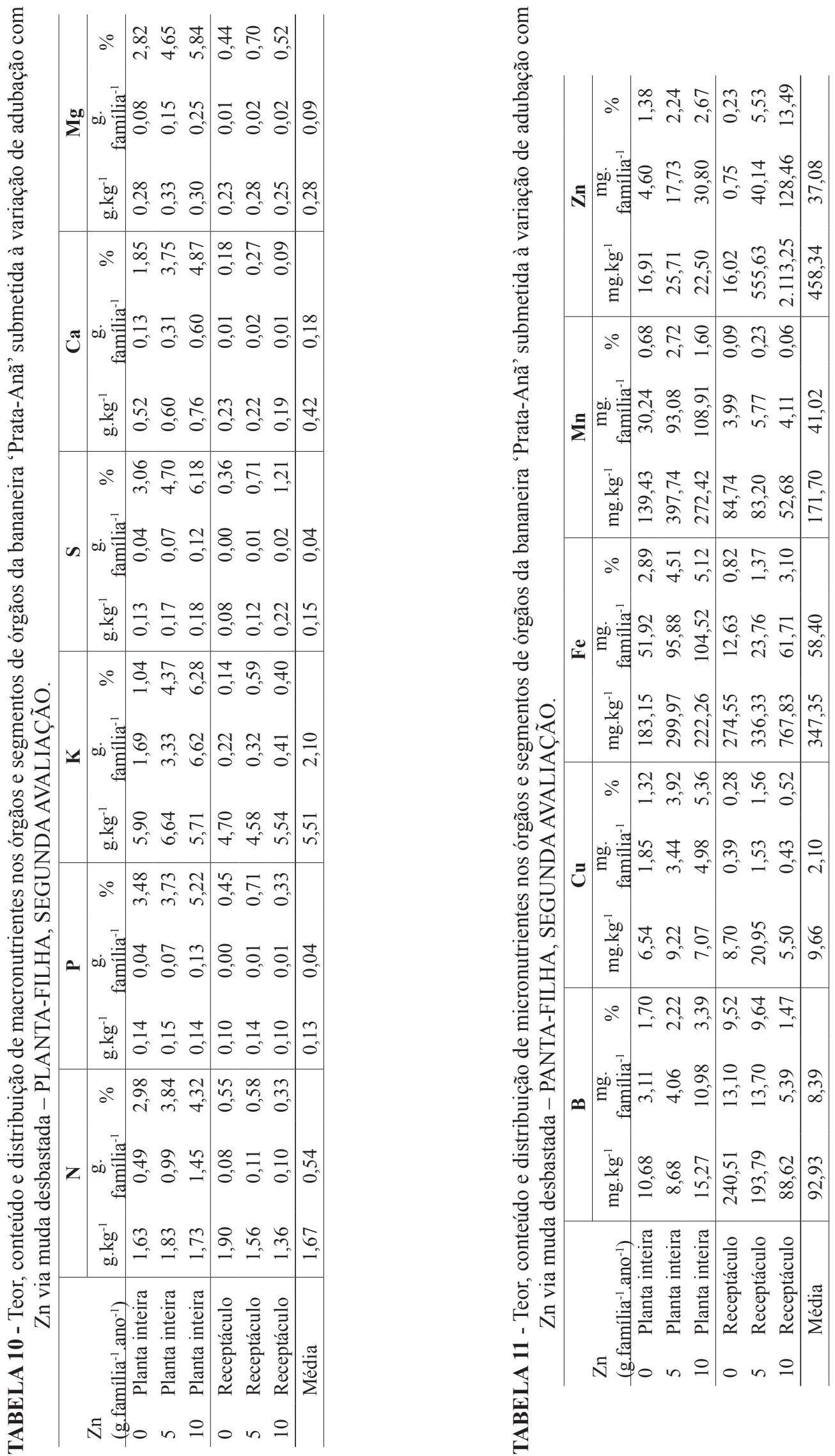


\section{CONCLUSÃO}

$\mathrm{O} \mathrm{Zn}$ fornecido via broto desbastado gera um gradiente nutricional na planta-mãe, havendo maiores concentrações deste no rizoma (principalmente na metade adjacente ao ponto de adubação) e menores teores nas partes superiores da planta. Esse resultado indica a entrada e a distribuição do Zn na planta, quando se utiliza essa forma de fornecimento.

\section{REFERÊNCIAS}

BLANCHAR, R. W.; REHM, G.; CALDWELL, A. C. Sulfur in plant material by digestion with nitric and perchloric acid. Soil Science Society of America Proceedings, Madison, v. 29, n. 1, p. 71-72, 1965.

BORGES, A. L.; OLIVEIRA, A. M. G.; SOUZA, L. S. Solos, nutrição e adubação. In: ALVES, E. J. (Coord.). A cultura da banana: aspectos técnicos, socioeconômicos e agroindustriais. Brasília: Embrapa- SPI, 1987. p. 197-260.

BRAGA, J. M.; DEFELIPO, B. V. Determinação espectrofotométrica de fósforo em extratos de solos e plantas. Revista Ceres, Viçosa, v. 21, p. 73-85, 1974.

DEFELIPO, B. V.; RIBEIRO, A. C. Análise química do solo: metodologia. 2.ed. Viçosa. MG: UFV, 1997. 26 p. (Cadernos de Extensão, 29).

FARIA, N. G. Absorção de nutrientes por variedades e híbridos promissores de bananeira. 1997. 66 f. Dissertação (Mestrado em Fitotecnia) - Escola de Agronomia, Universidade Federal da Bahia, Cruz das Almas, 1997.

GOMES, J. A.; HAAG, H. P.; NÓBREGA, A. C. Acumulação de matéria seca e micronutrientes pela planta-matriz da bananeira cv. Prata (Musa AAB, subgrupo Prata) em diferentes estádios de desenvolvimento. Anais da Esalq, Piracicaba, v. 45, part 1, p. 341-357, 1988.

JACOMINE, P. K. T.; CAVALCANTI, A. C.; FORMIGA, R. A.; SILVA, F. B. R.; BURGOS, N.; MEDEIROS, L. A. R.; LOPES, O. P.; MELO FILHO, H. R. L.; PESSOA, S. G. P.; LIMA, P. C. Levantamento exploratório: reconhecimento de solos do Norte de Minas Gerais - área de atuação da Sudene. Recife: EMBRAPA-SNLCS/ SUDENEDRN, 1979. p. 10-11.
LAHAV, E. Banana nutrition. In: GOWEN, S. (Ed.). Banana and plantains. London: Chapman \& Hall, 1995. p. 258-316.

LÓPEZ, M. A.; ESPINOSA, M. J. Manual de nutrición y fertilización del banano. Quito: INPOFOS, 1995. $82 \mathrm{p}$.

MALAVOLTA, E. Manual de química agrícola: adubos e adubação. 3. ed. São Paulo: Agronômica Ceres, 1981. $607 \mathrm{p}$

MALAVOLTA, E.; VITTI, G. C.; OLIVEIRA, S. A de. Avaliação do estado nutricional das plantas. Piracicaba: Potafós, 1997. 319 p.

MOREIRA, R. S. Banana: teoria e prática de cultivo São Paulo: Fundação Cargill, 1999. 1 CD-ROM.

MOREIRA, R. S. Adubação. In: SIMPÓSIO BRASILEIRO SOBRE BANANICULTURA, 4., 1998, Campo Grande. Anais... Jaboticabal: FUNEP, 2001. p. 252-325.

QUAGgiO, J. A.; PIZZA JUNIOR, C. T. Frutíferas tropicais. In: FERREIRA, M. E.; CRUZ, M. C. P. da; RAIJ, B. van; ABREU, C. A. de (Ed.). Micronutrientes e elementos tóxicos na agricultura. Jaboticabal: CNPq/ FAPESP/ POTAFÓS, 2001. p. 459-492.

RODRIGUES, M. G. V.; DIAS, M. S. C.; PACHECO, D. D. (Coord.). Bananicultura Irrigada: inovações tecnológicas. Informe Agropecuário, Belo Horizonte, v. 29, n. 245, p.1-120, 2008.

RODRIGUES, M. G. V.; RUGGIERO, C.; NATALE, N.; PACHECO, D. D. Nutrição e produção da bananeira 'Prata-Anã' adubada com zinco e boro diretamente no rizoma, via muda desbastada. Revista Brasileira de Fruticultura, Jaboticabal, v. 29, n. 3 , p. 645-651. 2007.

SILVA, E. B.; RODRIGUES, M. G. V. Levantamento nutricional dos bananais da região Norte de Minas Gerais pela análise foliar. Revista Brasileira de Fruticultura, Jaboticabal, v. 23, n. 3, p. 695-698, 2001.

SILVA, J. T. A. da; BORGES, A. L.; MALBURG, J. L. Solos, adubação e nutrição da bananeira. Informe Agropecuário, Belo Horizonte, v. 20, n. 196, p. 
21-36, 1999

SOTO BALLESTERO, M. Bananos: cultivo y comercialización. 2. ed. San José: Imprenta Lil, 2000. 1 CD- ROM.

TEDESCO, M. J.; VOLKWEISS, S. J.; BOHNEN, $\mathrm{H}$. Análises de solo, plantas e outros materiais. Porto Alegre: Departamento de Solos, Faculdade de Agronomia, UFRS, 1985. 186 p. (Boletim Técnico, 5).

TEIXEIRA, L. A.; SPIRONELLO, A.; QUAGGIO, J. A.; FURLANI, P. R. Banana. In: RAIJ, B. van;
CANTARELLA, H.; QUAGGIO, J. A.; FURLANI, A. M. C. (Ed.). Recomendações de adubação e calagem para o Estado de São Paulo. 2. ed. Campinas: Instituto Agronômico/Fundação IAC, 1997. p. 131-132. (Boletim Técnico, 100). 